\title{
Design and Development of a New Automated and High-Speed Gas Filling Systems
}

\author{
Zheng (Jeremy) Li \\ School of Engineering, University of Bridgeport, Bridgeport, CT 06604, USA \\ Correspondence should be addressed to Zheng (Jeremy) Li, zhengli@bridgeport.edu
}

Received 31 January 2011; Accepted 1 March 2011

Academic Editors: Y. Chen and Y.-H- Lin

Copyright () 2011 Zheng (Jeremy) Li. This is an open access article distributed under the Creative Commons Attribution License, which permits unrestricted use, distribution, and reproduction in any medium, provided the original work is properly cited.

This research is to describe the recent development of a new automated and high-speed gas filling system in industrial applications. It aims at the introduction, study, and analysis of automated and high-speed gas filling mechanisms in industry. Automation is not only significantly increasing the production speed but also more accurately controlling product quality. Automated mechanical system can maintain consistent quality, shorten lead time, simplify material handling, optimize work flow, and meet the product demand for flexibility and convertibility in production. Computer-aided engineering design can quickly model automated machinery systems, shorten the product development cycles, and improve engineering integral processes of product design, development, engineering analysis, and production. This paper introduces a newly developed automated and high-speed gas filling system and focuses on computer-aided design, modeling, and simulation of this new mechanism. Compared with the current conventional systems, this new automated gas filling system has more reliable sealing function and higher production rates. The prototype of this automated machinery system has also been tested for functional verification. Both computer-aided analysis and prototype testing results indicate that this automated and high-speed gas filling mechanical system works well with high production quantity and reliable product quality.

\section{Introduction}

Automation has brought revolution in industry and provides cost-effective and more flexible capability in controlling of machining systems [1]. It helps companies in economic enterprise improvement and replacement of human in heavy physical and dangerous working environment [2]. The fully automated machinery systems bring higher quality, better consistency, reduced lead times, simplified manufacturing processes, less product handling, and improved work flow in manufacturing and production lines.

Automated and high-speed mechanical system is a field of engineering dealing with different machine tool development integration of machinery systems and production equipments. It has been applied to manufacturing processes to perform many dangerous, heavy labor-related, and repetitive tasks [3]. The computer-aided design and modeling technology allows mechanical design teams to quickly and cost-effectively iterate the design process with better quality and reliable function. Through this technology, multiple design concepts can be reviewed and evaluated with no real prototype required until the product design is completed [4]. This paper introduces a new fully automated and highspeed gas filling mechanical system based on computer-aided simulation, analysis, and prototype testing.

\section{Automated and High-Speed Gas Filling System}

One critical feature in this automated mechanical system is to quickly and reliably seal high-pressure gas chamber during high-speed gas filling process. The normal sealing technologies include injecting gel into cartridge to seal gas chamber, shown in Figure 1, but it shows the poor sealing capacity in gas charging process.

In the newly developed gas filling and plug sealing mechanism, the plug is inserted into cartridge while gas is being charged into gas chamber, otherwise, gas will leak from chamber if cartridge is not being sealed simultaneously. 


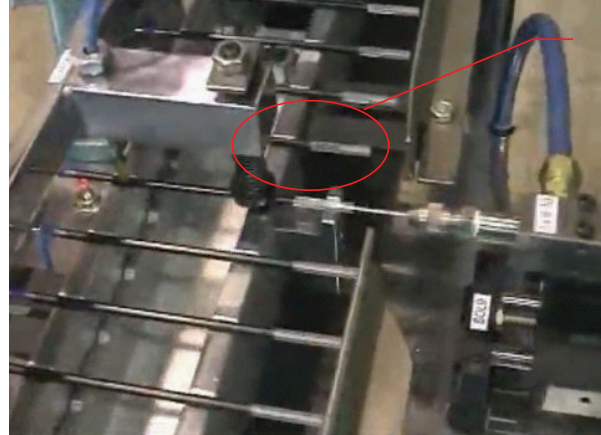

Gel is injected into cartridge for sealing after ink filling

No chamber of high air pressure

FIGURE 1: Gel sealing system.

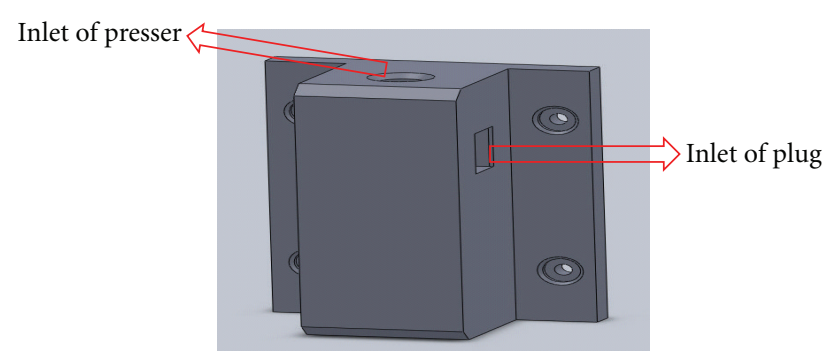

FIGURE 2: Plug entrance and gas inlet of prototype.

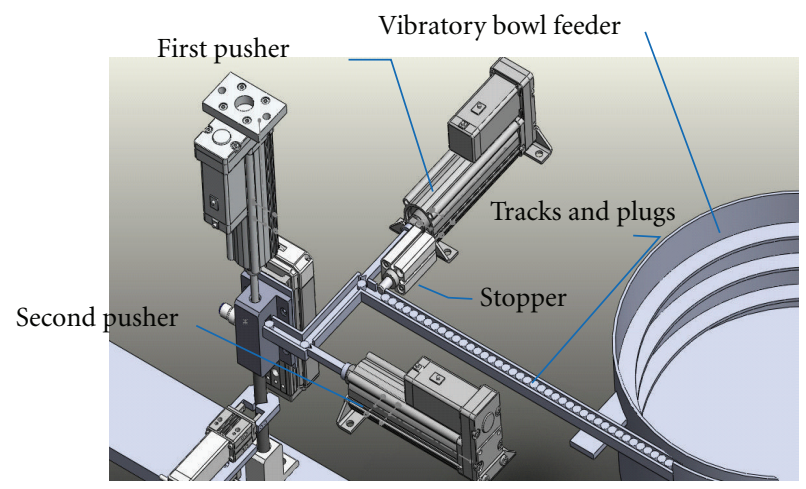

Figure 3: Automated plug delivery system.

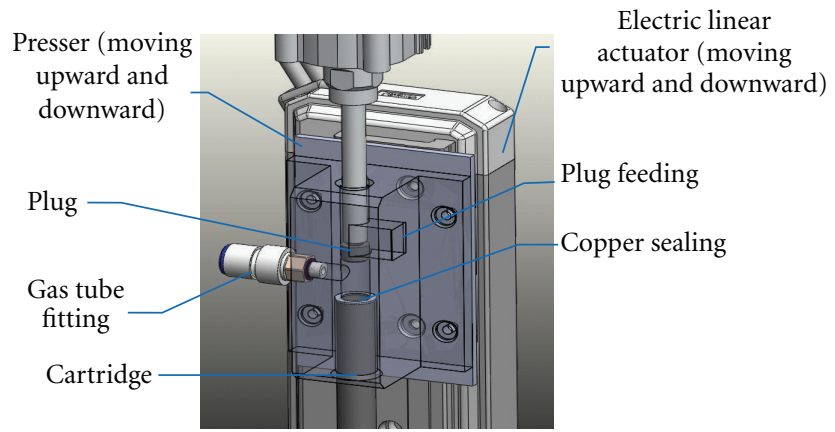

Figure 4: Plug assembly and gas charge process.
TABLE 1: Specification of actuator.

\begin{tabular}{cccccc}
\hline Size & $\begin{array}{c}\text { Screw } \\
\text { lead }\end{array}$ & \multicolumn{2}{c}{$\begin{array}{c}\text { Pushing force (lbf) } \\
\text { Step motor }\end{array}$} & $\begin{array}{c}\text { Max speed } \\
(\mathrm{mm} / \mathrm{s})\end{array}$ & $\begin{array}{l}\text { Stroke } \\
(\mathrm{mm})\end{array}$ \\
\hline \multirow{3}{*}{16} & 10 & 8.5 & 6.7 & 500 & \\
& 5 & 16.6 & 13.0 & 250 & 50 to 300 \\
& 2.5 & 31.7 & 25.0 & 125 & \\
\hline \multirow{3}{*}{25} & 12 & 27.4 & 7.9 & 500 & \\
& 6 & 53.5 & 16.2 & 250 & 50 to 400 \\
& 3 & 101.6 & 29.2 & 125 & \\
32 & 16 & 42.5 & & 500 & \\
& 8 & 83.2 & & 250 & 50 to 500 \\
& 4 & 158.9 & & 125 & \\
\hline
\end{tabular}

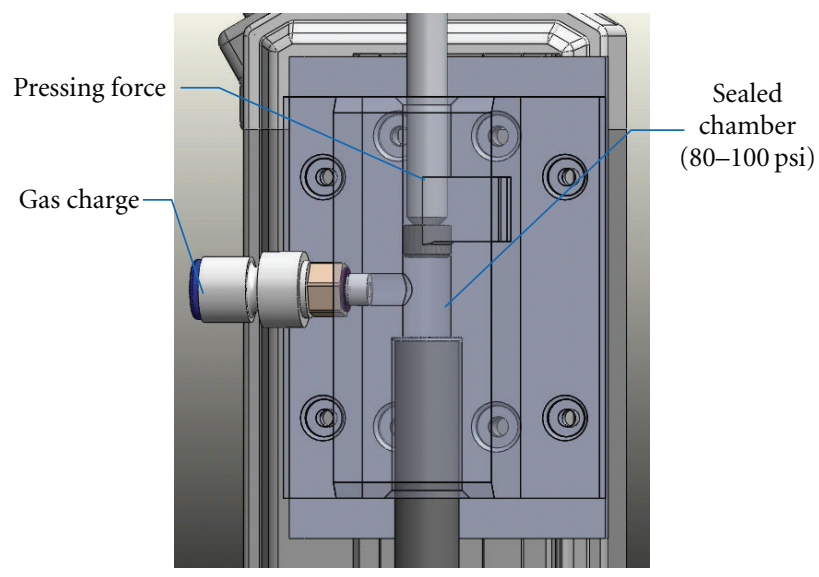

Figure 5: Sealing chamber.

Figure 2 shows the section of plug entrance and gas inlet of the prototype.

This subsection includes plug feeding inlet, central hole for plug assembly, and connecting tube fittings. When empty cartridge is automatically delivered to this subsection, the linear actuator drives subassembly section downward until it contacts the cartridge top surface. Meanwhile, multiple plugs are automatically fed to this subsection by feeding mechanism, shown in Figure 3.

The top pusher drives new plug through central hole in gas chamber until plug reaches 0.1 inch above the top surface of cartridge. The high-pressure gas is then charged into sealed chamber, and the top pusher continues driving plug downward to fully seal the cartridge, shown in Figures 4 and 5 .

Since the frictional force between plug and center hole is larger than gas pressure force, gas can be prevented from leaking at top surface of sealing unit.

If $F$ is gas pressure force,

$$
\begin{aligned}
P & =\frac{F}{S} \longrightarrow F=P \times S=P \times \pi \times\left(\frac{D}{2}\right)^{2} \\
& =100 \mathrm{psi} \times \pi \times\left(\frac{0.3 \mathrm{in}}{2}\right)^{2}=7.0686 \mathrm{lbf},
\end{aligned}
$$




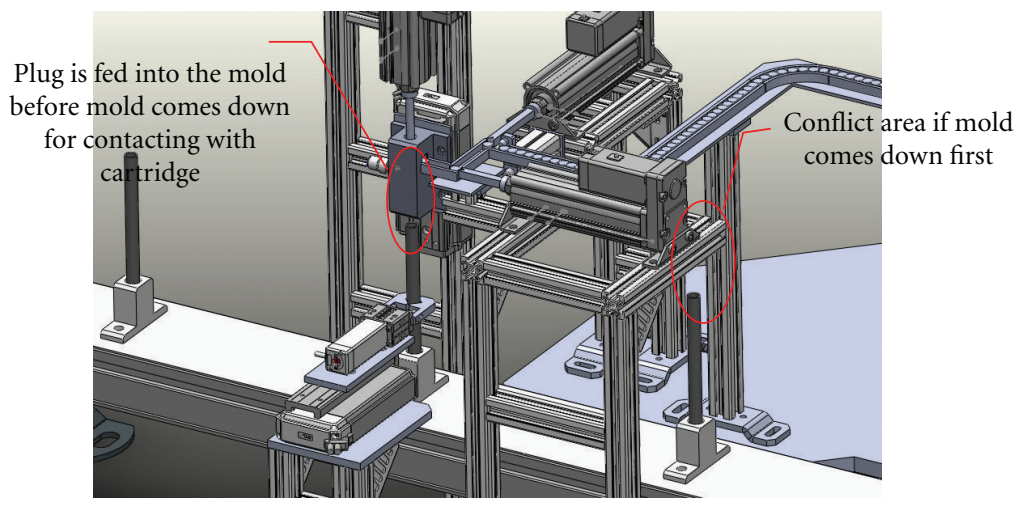

Figure 6: Prototype of automated and high-speed gas filling system.

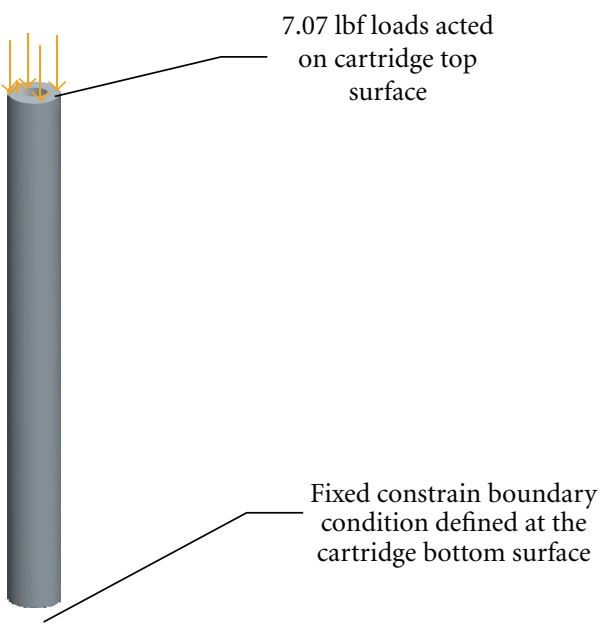

FIGURE 7: Load and boundary conditions of constrains on cartridge.

where $P$ is the maximum gas pressure, $S$ the bottom area of sealing plug, $D$ the diameter of sealing plug.

The actuator specification are shown in Table 1.

Since the pusher is mounted with this actuator, the pushing force $13 \mathrm{lbf}$ is larger than gas pressure force $7.08 \mathrm{lbf}$ and gas leakage can be prevented during gas charging process. All the above gas filling and plug sealing processes are automated and PLC controlled with high production rates.

Figure 6 shows the prototype of this newly developed gas filling system.

\section{Computer-Aided Stress Analysis on Cartridge Sealing System}

The above calculation indicated that the force of $7.07 \mathrm{lbf}$ is required to insert plug into cartridge. FEA software ProMechanica is used to determine the stress and strain of cartridge system during plug insertion process. The following diagrams show the results of structure and stress analysis. In this computer-aided 3D modeling, 7.07 lbf force is added at cartridge top surface and fixed constrain boundary condition is defined at cartridge bottom surface. Figures 7, 8, and 9 indicate that the maximum stress is 308.50 psi which is lower

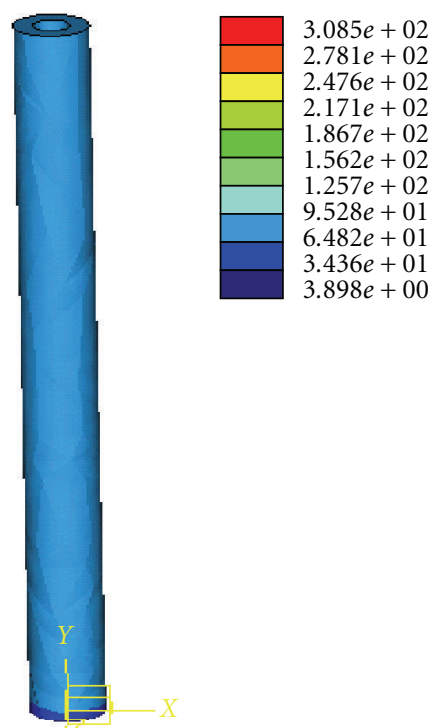

FIGURE 8: Stress distribution in cartridge.

than material allowable stress of 2900 psi, and maximum displacement is 0.0428 inch, that is, within material elastic safe region of 0.105 inch.

In Figure 7, $7.07 \mathrm{lbf}$ load acted on the cartridge top surface and fixed boundary constrain is defined at the cartridge bottom surface.

Also, the above computer-aided simulation results have been verified through prototype tests. The testing results indicate that this plug sealing mechanism works properly with no gas leakage, cartridge material can well handle plug insertion process with no damage, and cartridge deflection is within material elastic safety region.

Both computational simulation and prototype testing show the closed results with good sealing function that verifies the creditability and feasibility of this newly developed automated and high-speed gaseous filling system.

\section{Broader Impact}

Because of its safe, durable, and reliable functionality, this automated and high-speed gaseous charging technology can 


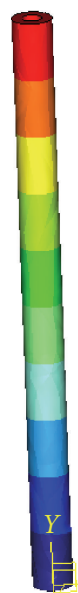

$4.277 e-02$

$3.849 e-02$

$3.421 e-02$

$2.994 e-02$

$2566 e-02$

$2.138 e-02$

$1.711 e-02$

$1.283 e-02$

$8.554 e-03$

$4.277 e-03$

$00 e-00$

Figure 9: Deflection in cartridge.

be applied to many other industrial applications including chemical gas, natural gas, pharmaceutics, cosmetics, aerospace, and biomedical engineering. More multiple functioning, sophisticated, and cost-effective gas filling systems could be designed and developed based on this new automated and high-speed gas filling system.

\section{Conclusion}

The application of automated and high-speed machinery technologies brings revolution to the industrial productions with flexible, reliable, and cost-effective manufacturing control methodologies and adds significant impact on modern industries. It is not only increasing the production quantity but also improving manufacturing quality. The study of this new automated and high-speed gas filling systems can help to understand and develop more efficient systems to produce gaseous products with consistent product quality, reduced production lead time, fast material handling process, and improved work flow. All these will satisfy customers on their product demand with flexibility and convertibility in manufacturing process and mass production.

\section{References}

[1] P. K. Kundu and I. M. Cohen, Fluid Mechanics, Academic Press, New York, NY, USA, 4th edition, 2008.

[2] S. A. Isaev, P. A. Baranov, N. A. Kudryavtsev, D. A. Lysenko, and A. E. Usachev, "Comparative analysis of the calculation data on an unsteady flow around a circular cylinder obtained using the VP2/3 and fluent packages and the Spalart-Allmaras and Menter turbulence models," Journal of Engineering Physics and Thermophysics, vol. 78, no. 6, pp. 1199-1213, 2005.

[3] C. Norberg, "Fluctuating lift on a circular cylinder: review and new measurements," Journal of Fluids and Structures, vol. 17, no. 1, pp. 57-96, 2003.

[4] M. M. Zdravkovich, "Flow around circular cylinders," Journal of Physics Application, vol. 2, no. 1, pp. 22-26, 2003. 

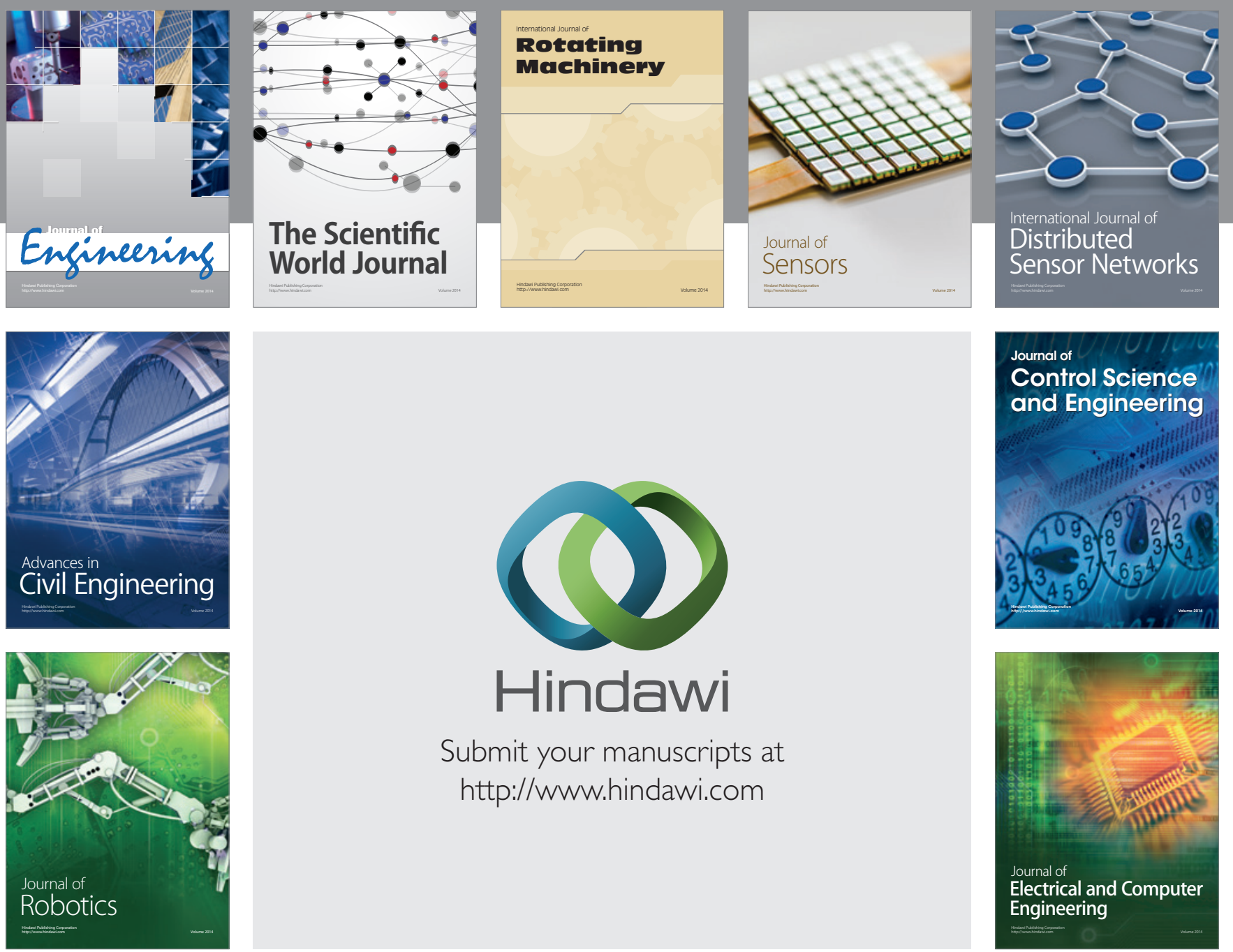

Submit your manuscripts at

http://www.hindawi.com
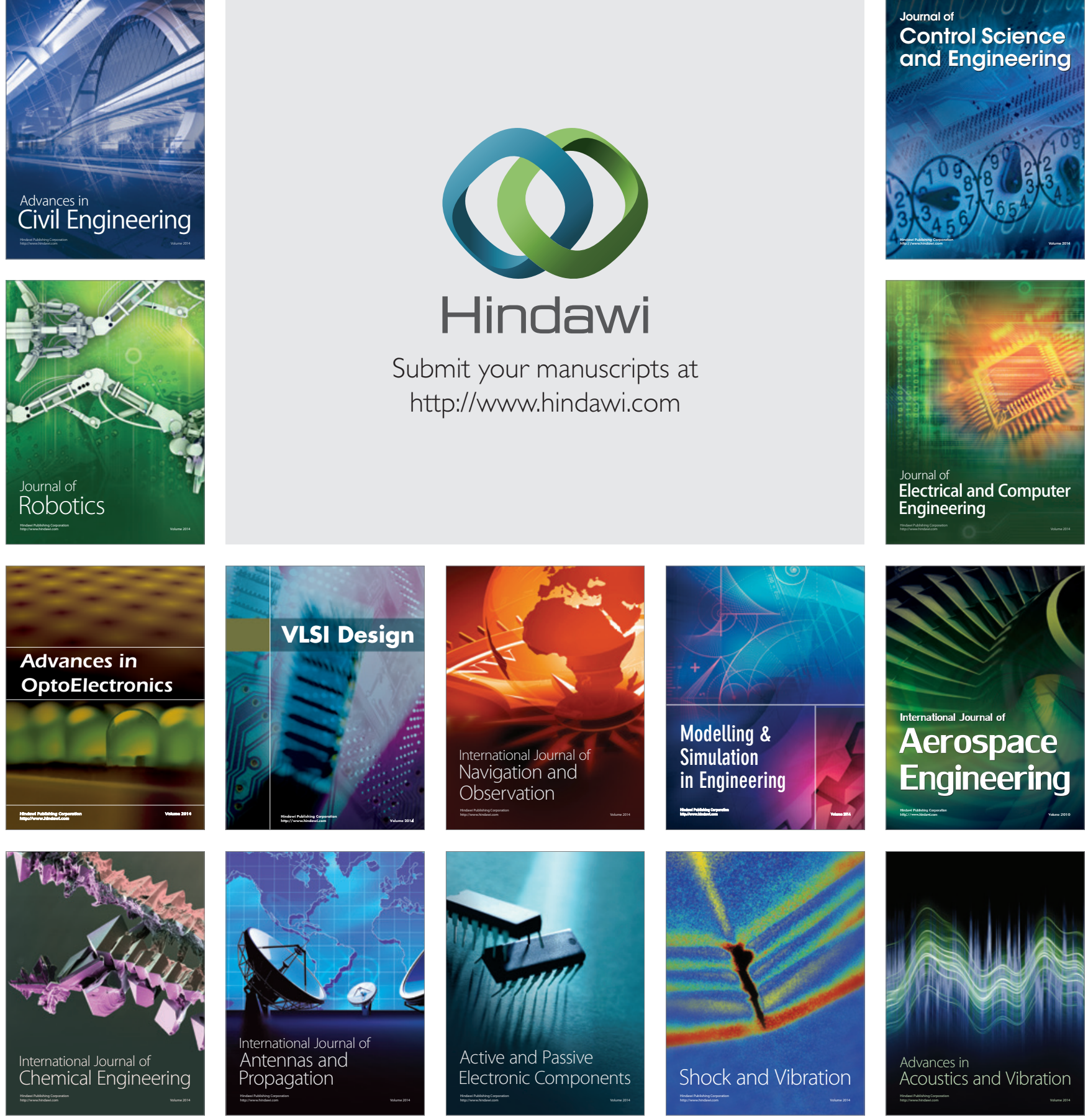